Photogallery

\title{
Genus-specific bleaching at Con Dao Islands, Southern Vietnam, June 2019
}

\section{Si Tuan VO*, Kim Hoang PHAN, Thai Tuyen HUA, Minh Quang THAI, and Xuan Ben HOANG}

Institute of Oceanography, Vietnam Academy of Science \& Technology, 01 Cau Da street, Nha Trang city, Vietnam

* Corresponding author: ST Vo

E-mail: vosituan@gmail.com

Communicated by Yoko Nozawa (Ecology Editor)

Keywords Genus specific bleaching, hard corals, susceptibility, adaptation, Con Dao islands

Coral communities in the shallow waters of Con Dao islands, located on the continental shelf of Southern Vietnam, were monitored in June 2019 when bleaching alert level 1 was announced by NOAA Coral Reef Watch (https:// coralreefwatch.noaa.gov/satellite/index.php) and the surface seawater temperature was recorded between $30-32^{\circ} \mathrm{C}$ in the field. We used the ReefCheck transect method (Hodgson et al. 2006) to record cover of bleached corals and non-bleached corals at two depths (shallow: 3-5 m and deep: 6-8 m) at 5 sites (EMS Fig. 1). The study sites were characterised by the dominance of hard corals with their cover more than $50 \%$ at 4 sites and around 25\% at Cua Ga. Overall, 32.5 $\pm 7.5 \%$ $($ mean $\pm \mathrm{SE}$ ) of hard corals (mean cover $=51.8 \%, \mathrm{SD}=23.7 \%)$ and $100 \%$ of soft corals $($ mean cover $=2.6 \%, \mathrm{SD}=4.5 \%)$ were observed to bleach. Bleaching at genus level was considered for common coral genera with their total cover (\%) as follows respectively: Acropora (17.3), Montipora (9.9) Porites (4.2), Diploastrea (2.4), Pachyseris (1.7), Pavona (1.6), Fungia (1.1), Favites (1.0), Pectinia (0.8) and Galaxea (0.6). The hard coral genera with most severe bleaching (all at 100\% bleached) included: Fungia (Fig. 1A), Pachyseris (Fig. 1B), Pavona (Fig. 1C), followed by Pectinia (93.8 $\pm 10.2 \%$ bleached; Fig. 1B) and massive Porites (69.9 $\pm 15.2 \%$ bleached; Fig. 1D). Other coral genera commonly found in Con

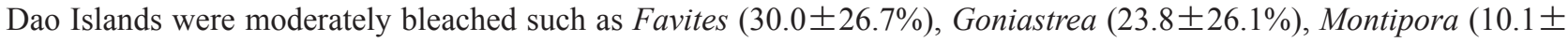
5.7\%; Fig. 1A). Two genera Galaxea and Diploastrea did not suffer bleaching. Acropora with most branch and tabulate colonies were less impacted both in deep and shalow waters $(0.9 \pm 1.3 \%$ bleached; Fig. $1 \mathrm{D}-\mathrm{F})$. Hard corals in deeper waters exhibited a higher susceptibility to bleaching than their shallow counterparts $(48 \%$ bleached in deeper transects compared with $15 \%$ in shallow transects). The findings were consistent with the higher abundance of the five most susceptible genera mentioned above in deeper (total mean cover $=17.5 \%)$ than in shallow $(2.2 \%)$ transects.

An earlier bleaching event at Con Dao islands in October 1998 resulted in 37.8\% of hard coral colonies bleached (Vo 2000). The 2019 event had both similarities and differences in impacts. Soft corals were the most susceptible in both events (100\% bleached) and Galaxea remained consistently unbleached. In 2019, Pachyseris and Fungia had much higher levels of bleaching than in 1998, when these genera were little affected (7.7\% and $8.3 \%$ bleached). In contrast, Diploastrea had no bleaching compared with 14\% bleached in 1998. Porites was severely impacted at both events with $57 \%$ bleached and many dead massive corals covered by filamentous algae were recorded in October 1998. Acropora were among the susceptible genera with $19 \%$ bleached colonies together with many dead colonies observed in October 1998 (Vo 2000). 

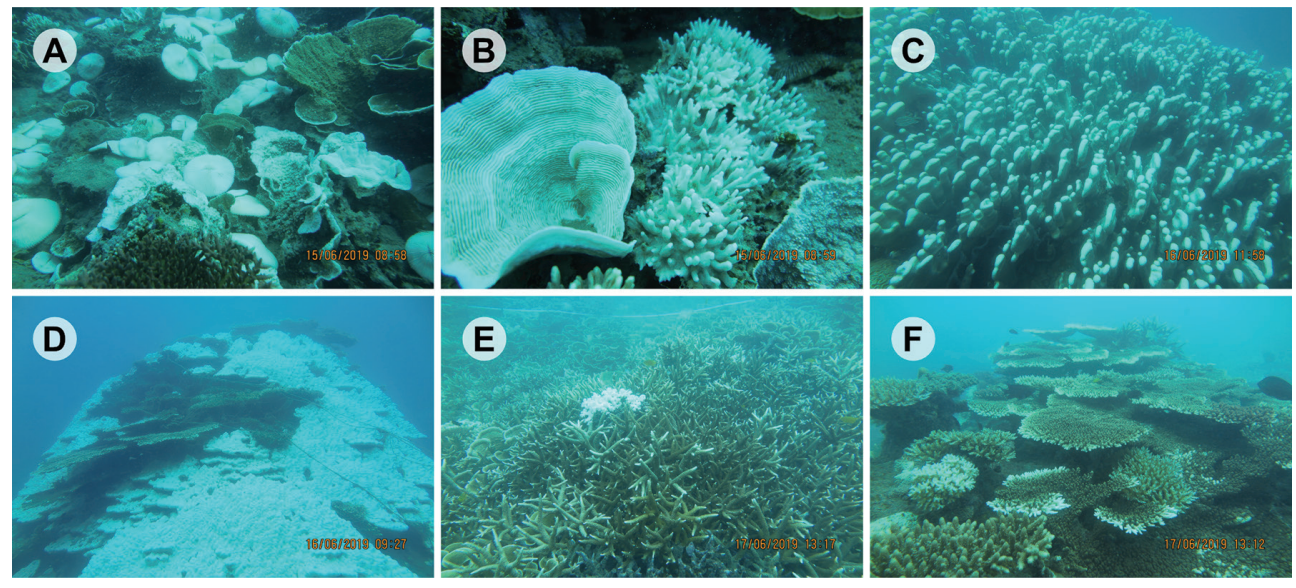

Fig. 1 (A) Severely bleached Fungia side by side with less affected Montipora (7 m deep); (B) Bleached Pachyseris and Pectinia corals (7 m deep); (C) Affected Pavona corals (8 m deep); (D) Non-bleached tabulate Acropora corals growing on severely bleached Porites ( $5 \mathrm{~m}$ deep); Acropora corals in (E) shallow (4 m deep) and (F) deep ( $8 \mathrm{~m}$ deep) transects without severe bleaching.

The present study highlights apparent shifts in susceptibility of some genera to bleaching from 1998 to 2019, especially of Acropora, given its great susceptibility to beaching events reviewed by Grimsditch and Salm (2006) and based on the previous study in Con Dao islands (Vo 2000). This genus was also severely impacted in 2017 bleaching event in Guam with 36\% live coral cover of staghorn Acropora lost (Raymundo et al. 2019). Whether these shifts are related to adaptation or acclimation remains as important questions. Further studies on changes of susceptibility of coral genera should aid scientific understanding and adaptive management in Con Dao National Park.

\section{Acknowledgement}

The study was conducted in the framework of USAid/PEER project (Grant\#618) on coral reef resilience and National project (Code: DTDL.CN-28/17) on sea-air-land interaction and environment variation in the SCS. We thank Con Dao National Park for its cooperation and support in studying coral reefs for a long time.

\section{References}

Hodgson G, Hill J, Kiene W, Maun L, Mihaly J, Liebeler J, Shuman C, Torres R (2006) Reef Check Instruction Manual: A Guide to Reef Check coral reef monitoring. California, USA: Reef Check Foundation, Pacific Palisades, 86pp Grimsditch GD, Salm, RV (2006) Coral reef resilience and resistance to bleaching. IUCN, Gland, Switzerland. 52pp Raymundo LJ, Burdick D, Hoot WC, Miller RM, Brown V, Reynolds T, Gault J, Idechong J, Fiifer J, Williams A (2019) Successive bleaching events cause mass motality in Guam, Micronesia. Coral Reefs 38: 677-700

Vo ST (2000) The corals at Con Dao Archipelago (South Vietnam): Before, during and after the bleaching event in 1998.

Proc 9th Inter Coral Reef Symp 2: 895-899

* ESM Fig. 1 can be downloaded from the J-STAGE website:

https://doi.org/10.3755/galaxea.22.1_27

Received: 11 May 2020/Accepted: 23 July 2020

(C) Japanese Coral Reef Society 